\title{
Measurement of Ground Motion near Piles during Driving
}

\author{
Richard Woods ${ }^{1}$, P.E., D.GE, Dist.M. ASCE, Adda Athanasopoulos-Zekkos ${ }^{2}$, A.M. ASCE, \\ Athena $\mathrm{Gkrizi}^{3}$, S.M.ASCE, Anthony Pietrangelo ${ }^{4}$, P.E., and Andrew Zimmerman ${ }^{5}$, M. ASCE \\ ${ }^{1}$ Professor Emeritus, Department of Civil and Environmental Engineering, University of Michigan, Ann \\ Arbor, MI 48109-2125; rdw@umich.edu \\ ${ }^{2}$ Assistant Professor, Department of Civil and Environmental Engineering, University of Michigan, Ann \\ Arbor, MI 48109-2125; addazekk@umich.edu \\ ${ }^{3}$ Graduate Student, Department of Civil and Environmental Engineering, University of Michigan, Ann \\ Arbor, MI 48109-2125; agkrizi@umich.edu \\ ${ }^{4}$ Geotechnical Construction Support Engineer, Michigan Department of Transportation, Lansing, MI \\ 48906; pietrangeloa@michigan.gov \\ ${ }^{5}$ CEO Civionics, LLC, Colorado Springs, CO, 80919; andy@ civionics.com
}

\begin{abstract}
Two types of vibration damage caused by driving piles have been reported in the literature: direct structural damage and damage due to settlement. Direct damage results from vibratory excitation of structures at amplitude exceeding the structural tolerance. Damage from settlement is a consequence from vibratory densification of loose soils resulting in total or differential settlement of structures. Problems of settlement due to pile driving have been experienced recently by the Michigan Department of Transportation (MDOT) during operations associated with replacement of deteriorating bridges. The work described here represents an attempt to understand the mechanisms of energy transfer from steel $\mathrm{H}$-piles driven with diesel hammers to the surrounding soil and the energy attenuation through the soil by measuring ground motion in the near vicinity of the pile. The main feature of this study consisted of installing motion transducers very close, within 0.5 foot, to piles and measuring the resulting ground motion during pile driving. Selection, fabrication, and installation of the transducers and preliminary measured pile driving vibrations are presented.
\end{abstract}

\section{BACKGROUND}

Damage to structures caused by impact pile driving has been the topic of many published papers as in O'Neill (1971); Clough and Chameau (1980); Lacy and Gould (1985); Picornell and del Monte (1985); and Dowding (1991). Two types of vibration damage caused by driving piles have been identified in those papers: direct structural damage and damage due to settlement. Direct damage results from vibratory excitation of structures at amplitudes exceeding the structural tolerance to cracking or other damaging phenomena. Settlement damage results from vibratory densification of loose sands resulting in total or differential settlement of structures or other civil engineering features. Vibrations that cause direct damage are often considered to be in the range of 0.5 to $2 \mathrm{in} / \mathrm{sec}$ particle velocity at the structure (Woods, 1997). Problems of settlement due to pile driving required two conditions: presence of loose soil (usually loose sand) and ground vibration exceeding threshold shear strain amplitude of about $0.01 \%$. Depending on soil conditions, particle motions much less than those necessary for direct damage can cause shear strain amplitudes in excess of the $0.01 \%$ threshold and cause settlement of loose sand. Recent experience by the Michigan Department of Transportation (MDOT) during replacement operations associated with deteriorating bridges has identified shakedown settlement of loose sand from pile driving as an important problem. The writers have been working with MDOT to understand and predict the potential for settlement from driving piles. 
The mechanisms of energy transfer from driven piles were postulated in the FHWA Synthesis \# 253 by Woods (1997) as shown in Fig. 1. This idealized schematic assumes a halfspace consisting of a homogeneous, isotropic, elastic material with a Poisson's ratio, $\mu$. Primary waves (P-waves) radiate from the pile tip and cylindrical waves ( $\mathrm{S}$-waves) radiate from the pile shaft and from the developing Rayleigh waves on the surface. However, this hypothesis has not been proven with physical ground motion measurements. Likewise, vibration attenuation in

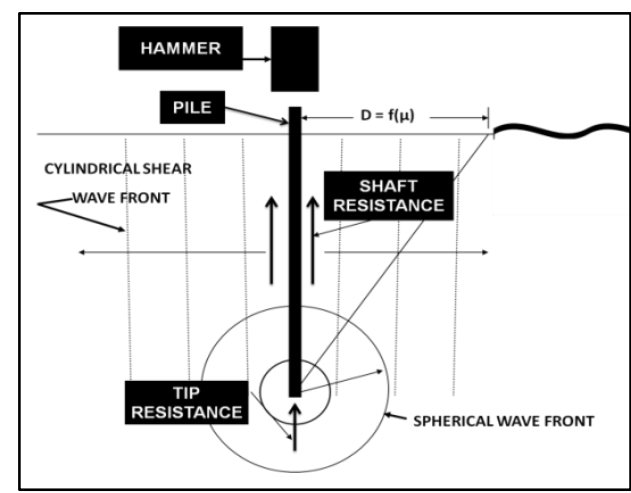

Figure 1 - Basic mechanisms of energy transfer from pile to soil (after Woods, 1997)

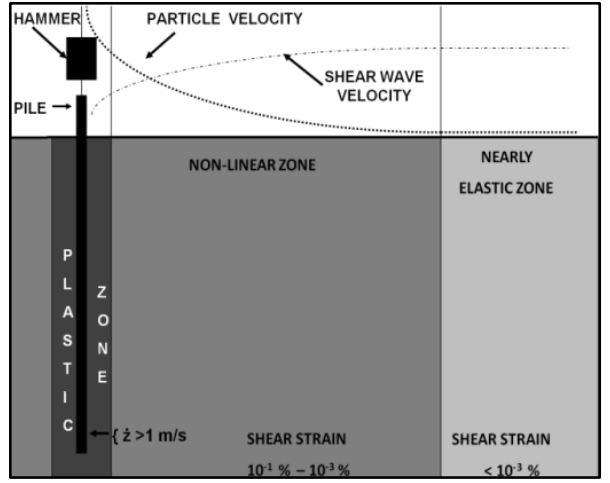

Figure 2 - Assumed soil behavior zones near driven pile (after Massarsch, 2002)

three general soil behavior zones, plastic, non-linear, and nearly elastic, shown in Fig. 2, are also unsubstantiated. Shearing strain, $\gamma$, is suggested for defining boundaries of these zones. Shear strain in the ground can be calculated from particle velocity (which is the subject of this work) divided by shear wave velocity which can be measured or inferred from standard blow count. To verify these assumed soil behaviors, measurements of ground motion in the vicinity of a driven pile are required and the literature does not report on measurements of this kind. The work described here represents a first attempt to make ground motion measurements in close proximity to driven H-piles.

By measuring ground motion at three distances from the pile, it was expected that a vibration decay curve could be developed from which an attenuation coefficient or coefficients could be developed to define the soil behaviors in Fig. 2. It was not considered feasible to determine the ground vibration precisely at the pile-soil interface, but Massarsch and Fellenius (2008) present an equation for predicting the maximum amplitude of soil motion at the pile-soil interface that depends on shearing strength of the soil:

$\dot{\mathrm{Z}}=\tau / \mathrm{V}_{\mathrm{s}} \rho$

where $\dot{z}$ is the peak particle velocity in the soil at the pile-soil interface, $\tau$ is the shearing strength of the soil, $V_{s}$ is the shear wave velocity in the soil at the contact with the pile and $\rho$ is the mass density of the soil. One preliminary goal of this research was to compare calculated values of the interface particle velocity from EQ 1 with projections back to the interface soil-pile interface from measured particle velocity from sensors embedded in the ground near the driven pile. In this way it was expected that the near pile attenuation of ground motion could be verified.

\section{SACRIFICIAL GROUND MOTION TRANSDUCERS}

Construction operations are not compatible with installation and recovery of buried transducers. Conductor cables are also vulnerable in the pile driving construction environment so 
it was determined to develop sacrificial transducer packages that could be pushed into the ground and not be recovered.

Two types of motion sensor cones were designed and fabricated to be pushed into the ground and not recovered. These sacrificial transducers consisted of single component (vertical) geophones and triaxial accelerometers. The least expensive approach was to use $4.5 \mathrm{~Hz}$ geophones (Fig. 3). The geophone cans, model RGI-20DX, were supplied by Racotech Geophysical Instruments. Since the range of ground motion was not known in advance, more expensive triaxial, MEMS based accelerometers were also prepared. Based on preliminary tests, it was estimated that ground acceleration could be as high as 5 g's so accelerometers with this capability were procured. Triaxial accelerometer units to meet this criterion were custom designed and fabricated by Civionics, LLC. Model MMA7361LCT triaxial, MEMS type accelerometers supplied by Freescale, Inc. with an acceleration range of $6 \mathrm{~g}$ 's were the basis of Civionics' design. A $3.3 \mathrm{~V}$ voltage regulator that allowed any voltage source from $4 \mathrm{~V}$ to $14 \mathrm{~V}$ was used to provide a zero level, $1.65 \mathrm{~V}(0-3.3$ volt range $)$ output with a sensitivity of $206 \mathrm{mV} / \mathrm{g}$. These components were mounted on a 1"x 1" PCB, as shown in Fig. 4.

\section{SENSOR CONES}

Sensor cones were machined from steel to be very robust so they could be pushed into the ground to their planned elevations. These cones had 60 degree tapered tips, a hollowed-out cylindrical center to house the sensors and a special adaptor that allowed downward pushing of the cone with rods from the drill rig, (Fig.5), but the adaptor could not apply a withdrawing force to the sensor cone so it was unrecoverable. Figure 6 shows a geophone potted into the push cone and Fig.7 shows the accelerometer chip being fitted into a cone cavity. The conducting cable from the sensors was fed upward through the adapter and hollow of the drill rods to the ground surface and to the data acquisition system, as shown in Fig. 8.

\section{SACRIFICIAL SENSOR INSTALLATION}

Pile driving contractors who had been awarded the contracts to build the replacement bridges at each of the selected sites recommended by MDOT were approached for their willingness to cooperate with the University of Michigan (U of M) research project. In each case the contractor agreed to drive an H-pile of the size typical for their site in a location where ground motion measurements could be made with minimal interruption of their operations but favorable for the $\mathrm{U}$ of $\mathrm{M}$ research.

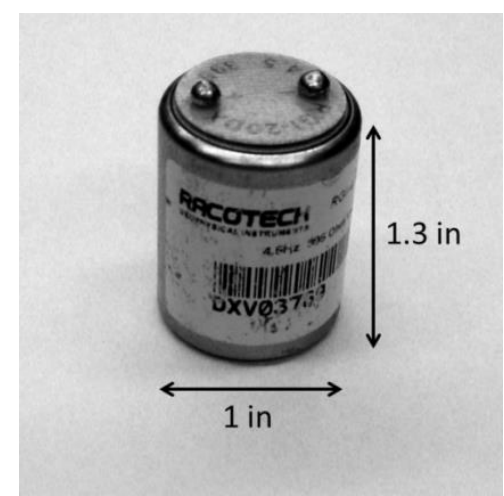

Figure $3-4.5 \mathrm{~Hz}$ geophone can

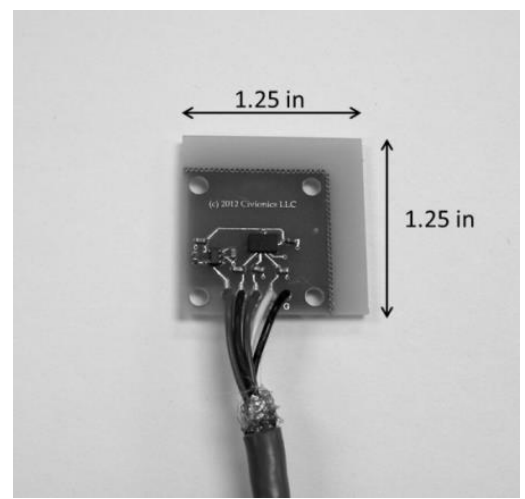

Figure 4 - Civionics Triaxial MEMS accelerometer on chip 


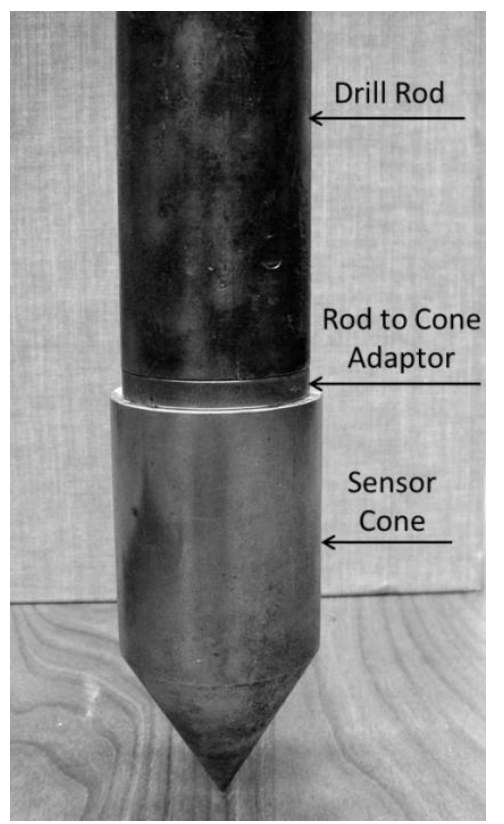

Figure 5 - Sacrificial sensor push cone, and drill rod

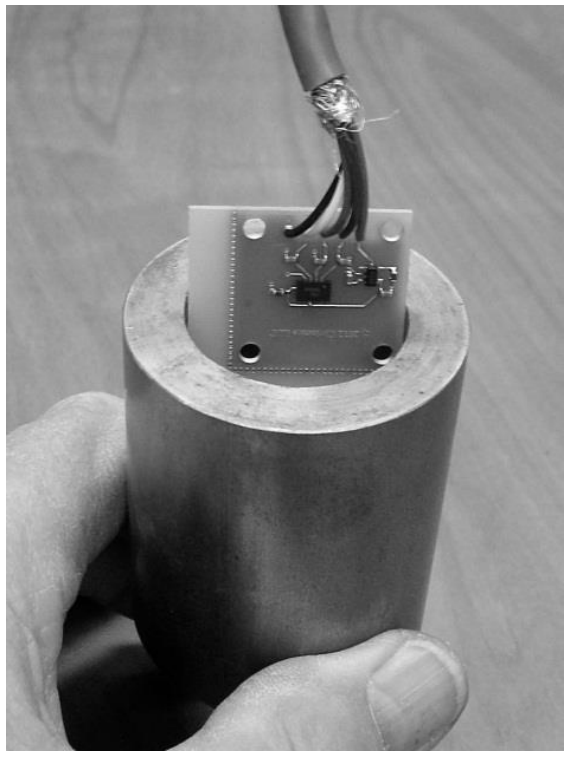

Figure 7 - Accelerometer chip being fitted into push cone cavity

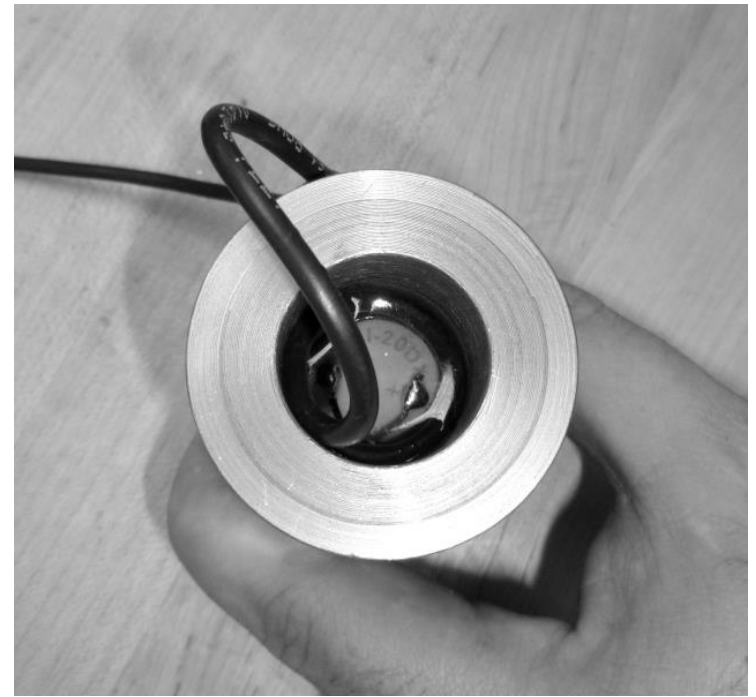

Figure 6 - Geophone potted in push cone cavity

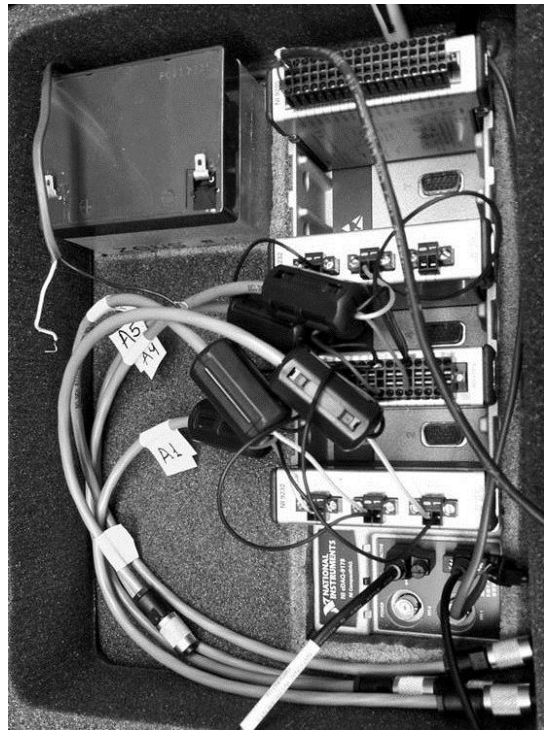

Figure 8 - Data acquisition system

The location of where the pile was to be driven was selected by the contractor and the plan positioning of the intended sensors was laid out on the ground by the $\mathrm{U}$ of $\mathrm{M}$ group. At each depth sensors were installed starting with the one closest to the pile and working outward from the pile for additional sensors. An MDOT drill rig was positioned over the closest to the pile 
sensor location and the sensor package pushed into the ground. Sensors were pushed using the hydraulic thrust capabilities of the drill rig (Fig. 9). When all sensors were installed, the pile was spotted over the planned location as shown in Fig. 10 and driven. Plastic bags containing coils of conductor cable on the ground surface in Fig. 10 identify the ground surface projection of embedded sensors.

Sites chosen for this work consisted generally of loose to medium dense sands so little difficulty was expected during installation of the sensors. However, initial attempts at installation of sensor cones resulted in breaking off of the conductor cables due to encountering unknown obstacles. Hydraulic crowd capabilities of the drill rigs and free, unsupported column action of the drill rod also limited how far the sensors could be pushed without bending the rods beyond the elastic range. As an alternate approach, installation of the sensor packages through the center of hollow stem flight augers was attempted. Difficulties were encountered with this approach as well because the sensor packages needed to be pushed below the lower end of the hollow stem augers to get the sensor cone below the zone of disturbance caused by the hollow stem auger's installation. Withdrawal of the center rod of the hollow stem auger and re-installation of the drill rod with the sensor package resulted in loss of either the sensor package or severing of the conductor cable. While each sensor's position in space was planned, in practice, the local ground conditions and installation process controlled the final depths of the sensors. A steep learning curve was experienced that resulted in successful installation of seven triaxial accelerometer sensor cones as shown in Fig. 11. A view of one of the sites prepared for collecting data from buried and surface sensors is shown in Fig. 12.

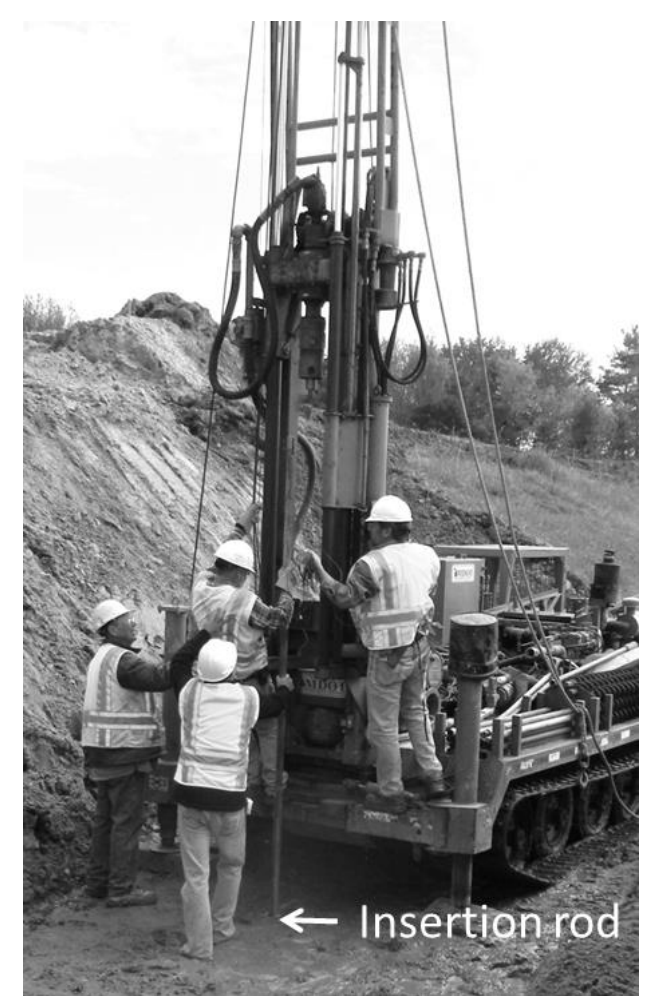

Figure 9 - All-terrain drill rig installing sensors using hydraulic thrust

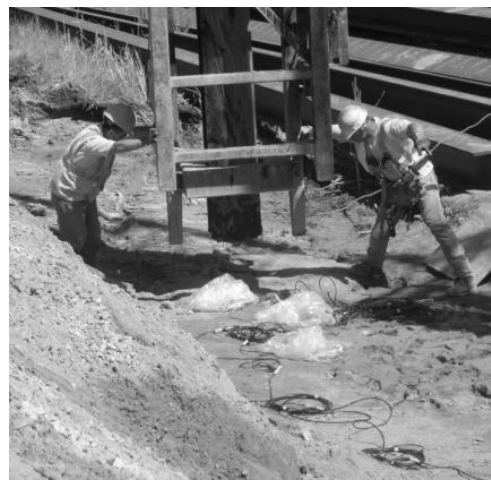

Figure 10 - Spotting pile and showing plastic bags containing cables from buried sensors 


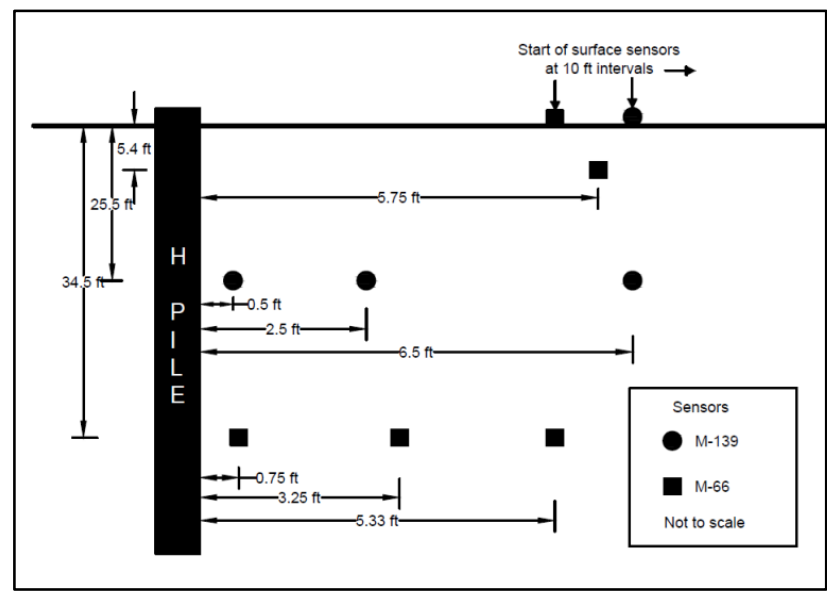

Figure 11- Schematic of embedded sensor cones at depth and with distance at two sites

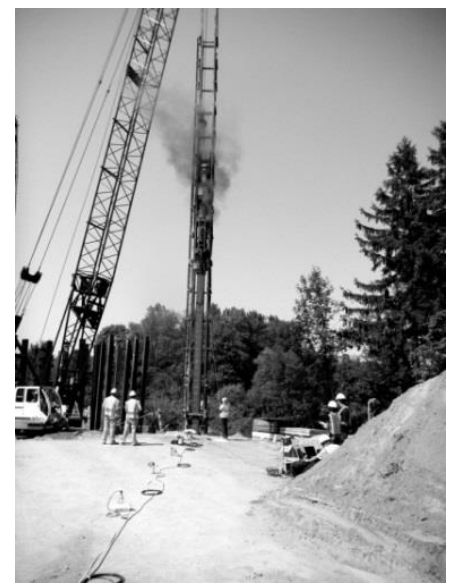

Figure 12 - Ground surface geophones on line with pile being driven

\section{SAMPLE OF RESULTS}

Three H-pile driving sites were instrumented and pile driving vibrations recorded. Measured vibrations from one of the three sites will be presented in preliminary form. A plan view of the M-139 site near Niles, Michigan showing the location of buried sensors and surface geophones is presented in Fig. 13. At this site five triaxial accelerometer packages were installed in the ground near the pile and four surface geophone packages were set along the ground surface to record surface waves. Figure 14a shows a simplified representation of the soil profile with soil descriptions and blow counts of a boring performed after the pile had been driven and within 5 feet of the driven pile. Accelerations of sensors at a depth of $25.5 \mathrm{ft}$. (intended depth of sensors was $20 \mathrm{ft}$. but loose sand would not "grab" the sensor cone at that depth) and at three distances from the pile as the pile tip reached each depth are shown in Fig. 14b. At the depths where the pile tip is above the accelerometers, the three sensors show moderately increasing amplitude with pile tip depth to within about 5 feet above the sensors, but after the pile tip reaches the depth of the sensors, the accelerations increase dramatically particularly for the sensor nearest to the pile. It can be seen that there are different behaviors of the three sensors at their common depth as the pile approaches from the top and as the pile departs to greater depths. There is little or no shaft contribution to the ground motion as the pile tip is still above the sensor, but contributions from both shaft and tip combine constructively after the pile tip reached and passed the depth of the sensor.

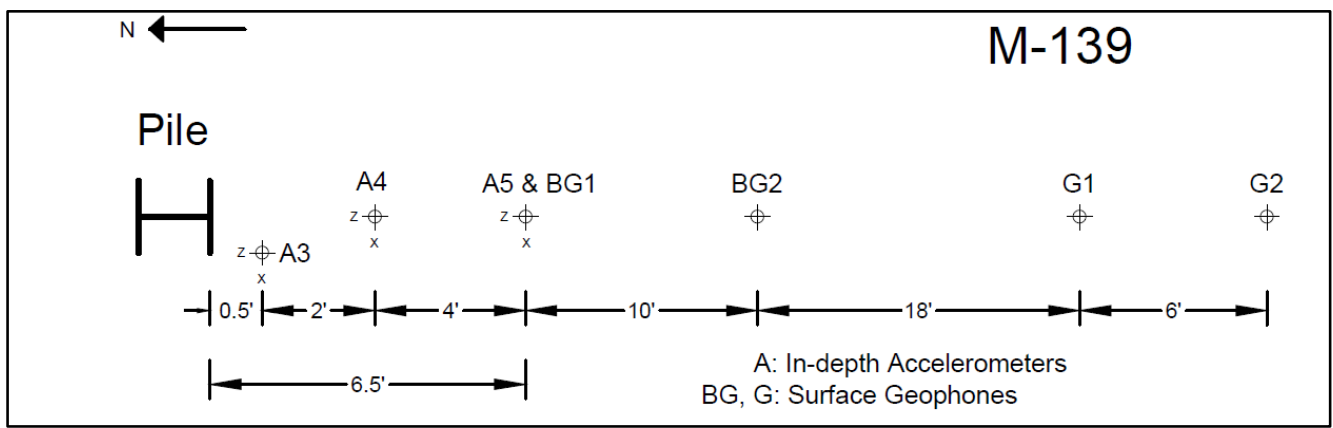

Figure 13 - Plan view of sensor locations at M-139 site, both buried and surface 

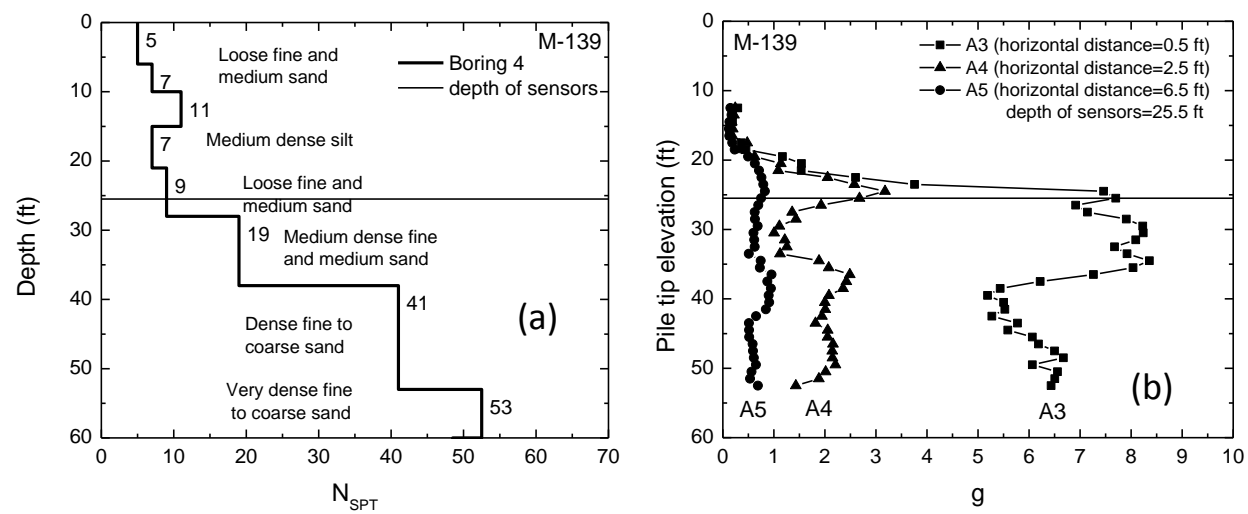

Figure 14 - (a) Boring log near pile after driving and (b) observed vertical accelerations at sensors at three depths as pile tip penetrates the ground

Another way of looking at the ground vibration amplitude as the pile tip penetrates the ground is shown in Figs. 15 a, b \& c. In these figures the peak particle velocity is plotted vs. diagonal distance (resultant of vertical and horizontal distances) from the pile tip to the buried sensor. Furthermore, data is plotted in Figs. 15 for two regions of the drive: where the pile tip is above the elevation of the sensors and where the pile tip is below the sensors. To interpret these figures, start at the lower right portion of Fig. 15a, for example, where the pile tip is furthest above the sensors and proceed upward to the left as the pile tip approaches the depth of the sensor. The amplitude increases smoothly to the level where the pile tip is at the same elevation as the sensors. Continue to follow the amplitude of vibration curve as the pile tip descends below the sensors and the vibration amplitude first makes a dip then increases and remains at the higher level throughout the remainder of the driving.

Figures 16 a \& b show attenuation curves for peak particle velocity in both arithmetic and logarithmic scales respectively developed from records of the three sensors at a common depth $(25.5 \mathrm{ft}$.) and vibration amplitude at the pile interface (called $0.1 \mathrm{ft}$ for convenience on $\log$ scale) estimated from EQ 1. These curves show the high rate of attenuation very near the pile and lesser rates of attenuation with distance from the pile. Figures $16 \mathrm{c} \& \mathrm{~d}$ show similar curves for the surface geophones. As more data of this type gathered, coefficients of attenuation and power function equations will be developed for various soils encountered.

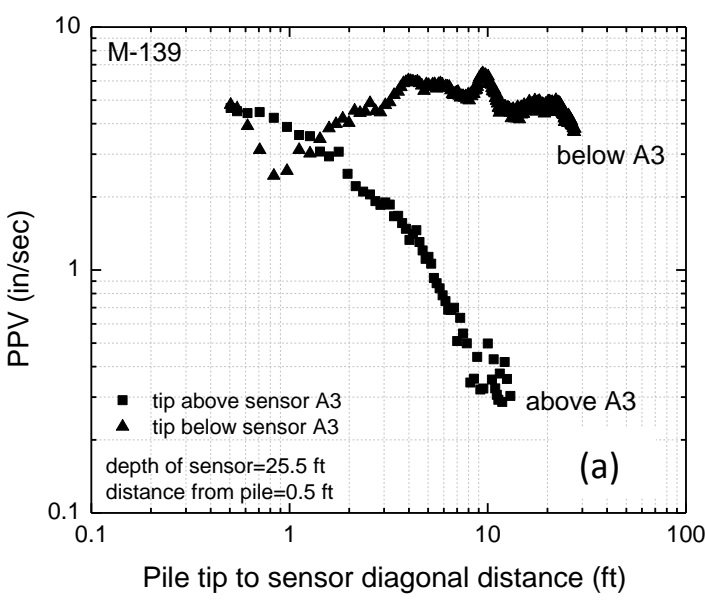

Figure 15a - Pile tip approaching from above and departing below depth of sensor A3 for vertical motion 

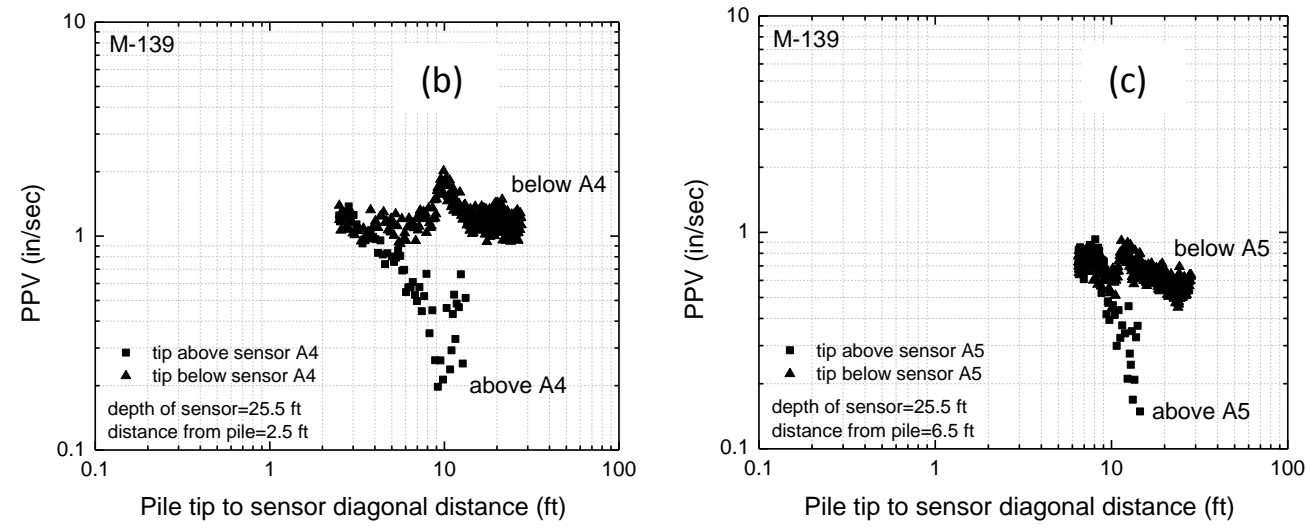

Figure $15 \mathrm{~b} \& \mathrm{c}$ - Pile tip approaching from above and departing below depth of sensor (b) A4 and (c) A5 all for vertical motion
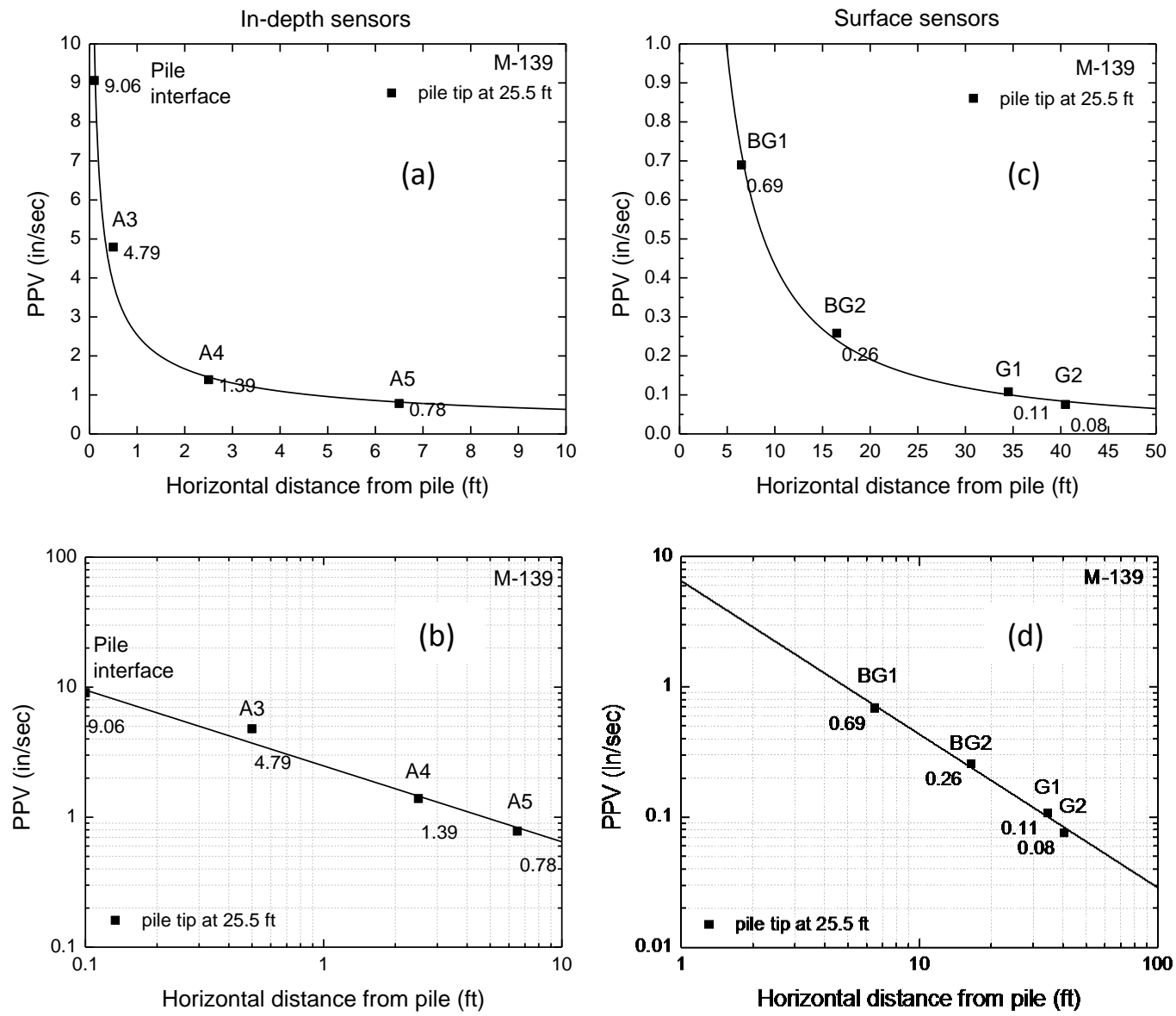

Figure 16 - Attenuation curves for vertical vibrations in the ground and on the surface 


\section{CONCLUSIONS}

To the writers knowledge this work represents the first example of installation of motion sensors at varying depths and very near to driven piles for the expressed purpose of measuring vibrations as the piles were being driven. Ground motion sensor packages that could be pushed into the ground and sacrificed after their use were designed, fabricated and installed in the ground very near to driven piles. Piles were driven at three, loose sand sites after installation of sensor cones at three depths and three radial distances from the pile. Measured vibrations show that sensors at different distances from the pile at the same elevation, record different amplitudes of vibration as the pile tip approaches and departs from the elevation of the sensors. The data suggests to the writers that when the pile tip is far above the sensor, pile tip generated vibrations mainly affect the sensors but as the tip gets closer to the sensor level, contribution from the pile shaft also reaches the sensor. After the pile tip passes the depth of the sensor, both pile tip and shaft generated vibrations combine constructively for larger vibrations. The vibration levels after the tip passes the elevation of the sensors stays relative constant suggesting that the pile tip which is getting further from the sensor contributes less and less to the vibration than the shaft. This response is not contradictory to the hypothesis at the beginning of this paper as suggested in Figs. 1 and 2. It is further anticipated that attenuation data will help define boundaries of vibration decay with radial distance from the driven pile. Additional sites will be studied and more exhaustive analyses made and reported in future publications.

\section{ACKNOWLEDGEMENTS}

This work was performed under contract 2010-0296 with the MDOT, project \#114128, dates $10 / 1 / 2011-03 / 31 / 13$

\section{REFERENCES}

Clough, G.W. and Chameau, J-L. (1980). "Measured Effects of Vibratory Sheetpile Driving." Journal of the Geotechnical Engineering Division, ASCE, 106(GT 10), 1081-1099.

Dowding, C.H. (1991) “Permanent Displacement and Pile Driving Vibrations." Proceedings, $16^{\text {th }}$ Annual Member Conference of the Deep Foundations Institute, Chicago, Oct. 7-9, 67-84.

Lacy, H.S. and Gould, J.P. (1985). "Settlement From Pile Driving in Sands.” Vibration Problems in Geotechnical Engineering," Proceedings of a Symposium edited by Gazetas and Selig, sponsored by the Geotechnical Engineering Division in conjunction with the ASCE Convention, Detroit Michigan, October 22, 152-173.

Massarsch, K.R. (2002). "Effects of Vibratory Compaction." TransVib 2002 - International Conference on Vibratory Driving and Deep Soil Compaction, Louvain-la-Neuve, 33-42.

Massarsch, K.R. and Fellinius, B.H. (2008)." Ground Vibrations Induced by Impact Driving." Proccedings of $6^{\text {th }}$ International Conference on Case Histories in Geotechnical Engineering, Edited by S. Prakash, University of Missouri-Rolla, Rolla, Mo, August 12-16, Arlington, VA, 38.

O’Neill, D.B. (1971). "Vibration and Dynamic Settlement from Pile Driving.” Proceedings of the Conference on Behavior of Piles, Institute of Civil Engineers, London, 135-140. 
Picornell, M. and del Monte, E. (1985). "Pile Driving Induced Settlements of a Pier Foundation. "Vibration Problems in Geotechnical Engineering, Proceedings of a Symposium edited by Gazetas and Selig sponsored by the Geotechnical Engineering Division, in conjunction with the ASCE Detroit, Michigan, Convention, October 22, 174-186.

Schwab, J.P. and Bhatia, S.K. (1985). "Pile Driving Influence in Surrounding Soil and Structures." Civil Engineering for Practicing and Design Engineers, Pergamon Press Ltd., 4(8), 641-684.

Woods, R.D. (1997). Dynamic Effects of Pile Installations on Adjacent Structures, Synthesis of Highway Practice NCHRP\#253, Transportation Research Board, National Research Council, National Academy Press, 86 p. 